\title{
Xylene isomerization in an extractor type Catalytic Membrane Reactor
}

\author{
Lizelle van Dyk ${ }^{1,2}$, Leon Lorenzen ${ }^{1}$, Sylvain Miachon ${ }^{2, *} \&$ Jean-Alain Dalmon ${ }^{2}$ \\ 1. University of Stellenbosch, Stellenbosch, South Africa \\ 2. Institut de Recherches sur la Catalyse, CNRS, Villeurbanne, France
}

to whom correspondence should be addressed: smiachon@catalyse.cnrs.fr

\begin{abstract}
A zeolite / alumina pore plugging membrane was used to successfully separate xylene isomers. It was then applied as a selective membrane in an extractor type Catalytic Membrane Reactor (CMR), used to enhance the xylene isomerization reaction selectivity towards para-xylene. The results of the CMR in different configurations (permeate-only and combined permeate-\&-retentate mode) were compared to conventional fixed-bed reactor results. In both cases, the selectivity was significantly enhanced (up to $100 \%$ in permeate-only mode). In the combined mode, the CMR also provided a net increase in productivity over the conventional reactor.
\end{abstract}

\section{Keywords:}

para-xylene, meta-xylene, ortho-xylene, isomerization, zeolite membrane, Catalytic Membrane Reactor, extractor, selectivity, productivity.

\section{Introduction}

In 2003 the worldwide demand for xylenes was about 22 million tons, with para-xylene (a precursor for polyesters) holding $80 \%$ of the market share [1]. Principal sources of xylene isomer mixtures are catalytically reformed naphthas and pyrolysis distillates [2], with the distribution of xylene isomers being approximately $50-60 \%$ of meta-xylene and $20-25 \%$ ortho- and para-xylene. In order to meet the para-xylene demand the much less used ortho- and meta-xylenes are converted via the xylene isomerization reaction, a major industrial process for this aromatic [3]. Xylene isomerization is a thermodynamic equilibrium restricted reaction, and therefore total conversion is impossible in conventional conditions. Equilibrium product distributions in the standard state (atmospheric pressure) for temperatures $250-1500 \mathrm{~K}$, range from $63-47 \%$ for meta-xylene, $13.4-30 \%$ for ortho-xylene and $23.6-23 \%$ for para-xylene [4].

Separation of para-xylene from its isomers is essential, but this is difficult due to their close boiling points. Paraxylene $\left(T_{b}=411.3 \mathrm{~K}\right)$ and meta-xylene $\left(T_{b}=412.1 \mathrm{~K}\right)$ are normally separated by crystallization, selective adsorption or chromatographic techniques. Recent research efforts focus on using MFI-zeolite membranes for xylene separation, a potentially more energy-efficient separation method [5-8]. The MFI zeolite pore structure consists of straight, circular pores $(0.54 \times 0.56 \mathrm{~nm})$, interconnected with sinusoidal, elliptic pores $(0.51 \times$ $0.54 \mathrm{~nm}$ ) [9]. These pore sizes are close to the kinetic diameter of para-xylene $\left(\mathrm{d}_{\mathrm{k}}=0.58 \mathrm{~nm}\right)$, and it is expected that its bulkier isomers $\left(\mathrm{d}_{\mathrm{k}}=0.68 \mathrm{~nm}\right)$ would diffuse at a slower rate, and adsorb to a lesser extent in the MFI framework due to their size and shape [6].
A number of research groups have carried out studies in this area with different results. Baertsch et al. [5] studied permeation of $\mathrm{p}$ - and o-xylene through silicalite- 1 membranes containing large amounts of non-zeolite pores. They found that for a mixture of $\sim 3 \mathrm{~mol} \% \mathrm{p}$ xylene, $3 \mathrm{~mol} \%$ o-xylene and $94 \mathrm{~mol} \% \mathrm{He}$ over the temperature range $380-480 \mathrm{~K}$, no separation occurred. Keizer et al. [10] reported separation factors of p-/oxylene as a function of time between 298 and $473 \mathrm{~K}$ and gave values of $\sim 1$ at $298 \mathrm{~K}$ to $>200$ at $375-415 \mathrm{~K}$ with a maximum at $\sim 400 \mathrm{~K}$. The separation factor was 25 at $473 \mathrm{~K}$. The partial pressures of components in the feed were low (p-xylene $0.31 \mathrm{kPa}$, o-xylene $0.26 \mathrm{kPa}$ ). A maximum p-xylene flux at $400 \mathrm{~K}$ was said to be due to opposing effects of adsorption and diffusion. Gump et al. [9] studied the fluxes of aromatic molecules (p-xylene, oxylene and benzene), through several molecular sieve membranes (SAPO-5, SAPO-11 and mordenite) as well as three types of MFI membranes (silicate-1, ZSM-5 and boron substituted ZSM-5), as a function of pressure and temperature. They found that surface diffusion and what they identified as activated gas transport were the controlling mass transfer mechanisms for MFI membranes. Boron-substituted ZSM-5 membrane displayed the highest $\mathrm{p}$-xylene/o-xylene separation, up to 60 , obtained at $425 \mathrm{~K}$ for partial feed pressures of $2.1 \mathrm{kPa}$ per isomer. Higher pressures of $\mathrm{p}$-xylene were reported to distort the membrane framework, leading to higher o-xylene permeation and reduced separation.

An extensive study of xylene vapour permeation was performed by Xomeritakis et al. [6,11,12]. Single gas permeation tests at feed partial pressures of 0.86 and $0.64 \mathrm{kPa}$ for $\mathrm{p}$-xylene and o-xylene were done in the temperature range 295 to $548 \mathrm{~K}$ for c-oriented $\mathrm{MFI}$ membranes. It was found that $\mathrm{p}$-xylene permeance displayed weak temperature dependence, while o-xylene 
permeance displayed a minimum at $373 \mathrm{~K}$. Also, as the partial pressure of $\mathrm{p}$-xylene in the feed mixture was increased from 43 to $430 \mathrm{~Pa}$, the p-/o- xylene separation factor dropped from 48 to 3 . In order to get rid of defect influence, Sakai et al. [7] used self-supporting MFI zeolite membranes of a thickness between 60 and $130 \mu \mathrm{m}$. The p-xylene permeation flux showed a maximum at $473 \mathrm{~K}$ and a partial pressure at $0.3 \mathrm{kPa}$, and was described by the competitive effects between equilibrium adsorption and diffusivity. The permeation of $\mathrm{m}$ - and o-xylene was small, and almost constant between 473 and $673 \mathrm{~K}$. The separation factors of p- to $\mathrm{m}$-xylene and $\mathrm{p}$ - to o-xylene reached a maximum value of 250 at $473 \mathrm{~K}$. On the other hand, high-pressure, hightemperature gas separation of xylenes were carried out by Hedlund et al. [13] using ultra thin MFI films $(0.5 \mu \mathrm{m})$ on porous $\alpha$-alumina supports produced by a two-step support masking technique, and a monolayer of colloidal nucleation seeds, followed by in situ hydrothermal growth. High permeance values were obtained (up to $0.6 \mu \mathrm{mol} / \mathrm{s} / \mathrm{m}^{2} / \mathrm{Pa}$ at $373 \mathrm{~K}$ ), together with $\mathrm{p}$-/o-xylene separation factors somewhat lower than expected (3 to 17) [14]. Similar interesting results were obtained recently by Lai and co-workers $[15,16]$.

Separation of para-xylene from its isomers is therefore possible through MFI-zeolite membranes. However, the presence of defects shows a strong influence on separation factors found in the literature, particularly at higher temperatures. In particular, supported zeolite films may suffer from defects opening during calcinations or temperature increase, as a consequence of the difference in thermal expansion coefficient between the zeolite and the support [7]. We show here the use of a zeolite /alumina nanocomposite membrane of the pore-plugging type.

Catalytic membrane reactors (CMRs) have been classified, in previous publications from our team, into three groups, depending on the function of the membrane: extractor, distributor and contactor [17]. By using a membrane capable of separating $\mathrm{p}$-xylene from the mixture of the three isomers, we propose to study the behaviour of the catalytic reaction taking place in the CMR. Therefore, this paper reports on the use of an extractor type CMR for the selectivity enhancement of the meta-xylene isomerization reaction towards paraxylene. Nevertheless, whereas extractor CMRs are commonly reported to enhance conversion, this work concentrates on improving selectivity.

\section{Experimental}

\section{Materials}

The MFI-zeolite membrane was synthesized in the wall of a porous ceramic tubular support (Pall-Exekia T1-70), consisting of three macroporous $\alpha$-alumina layers (from outer to inner side, respective average pore sizes: $12,0.8$, $0.1 \mu \mathrm{m}$ and thicknesses $1500,40,20 \mu \mathrm{m})$. It had an outer diameter of $10 \mathrm{~mm}$, inner diameter of $7 \mathrm{~mm}$ and an effective membrane length of $13 \mathrm{~cm}$. The MFI membrane was obtained by synthesis of zeolite crystals inside the pores of the macroporous tubular support (pore-plugging method) $[18,19]$. The MFI zeolite precursor solution was obtained by mixing silica (Aerosil 380) and a template (tetrapropylammonium hydroxide, TPAOH). After a 3day ageing period, the solution was poured in a Teflonlined autoclave containing the porous ceramic tube. Hydrothermal synthesis was then performed at $443 \mathrm{~K}$ for 3 days, and the membrane was calcined at $773 \mathrm{~K}$ under airflow. Low temperature butane / hydrogen separation through the membrane showed it could be considered close to defect-free (i.e. the transport through the membrane is controlled by the micropores of the MFI structure).

The catalyst (Pt on zeolite) was a commercial xylene isomerization catalyst (ISOXYL) from Süd-Chemie. The catalyst was diluted with kaolin to $5 \mathrm{wt} \%$ of the original and extruded into ca $2-\mathrm{mm}$ pellets, with a labscale extruder. The same mass of $2.18 \mathrm{~g}$ of the obtained solid was used in every experiment. Before catalytic use, the solid was activated in situ under $\mathrm{H}_{2}$ flow at $673 \mathrm{~K}$ for 3 hrs.

Anhydrous xylene isomers were purchased from SigmaAldrich: meta-xylene $99+\%$, para-xylene $99+\%$ and ortho-xylene $97 \%$.

\section{Set-up}

Figure 1 shows a schematic diagram of the experimental set-up used for the separation tests, as well as the catalytic membrane reactions. The xylenes were fed as gas phase diluted in nitrogen, using two saturators in series. The temperature in the first saturator was kept $5 \mathrm{~K}$ higher than the second one, in order to ensure precise vapour saturation. The flow through the compartments could be either co- or counter current (valve 3 ). The carrier gas, and sweep gas flow rates were controlled with Brooks mass flow controllers (FC). The internal pressure was measured by help of a pressure gauge (Keller PAA23). The trans-membrane or differential pressure between the internal and external compartments of the reactor was measured (Keller DP22), and could be manually regulated by using valves $11 \mathrm{a}$ and $\mathrm{b}$. The flow rates were measured with a soap bubble flow meter. All the pipes in the system were heated using heating tape and kept at $373 \mathrm{~K}$ in order to prevent any xylene condensation, and ensure correct xylene vapor pressure values. The compositions of the feed, permeate and retentate streams were analyzed on-line with a gas chromatograph (Shimadzu, GC 14A) equipped with a FID detector and a capillary column (Solgel-WAX, $\mathrm{SGE})$. Reactor by-pass was possible if needed. 
L. van Dyk, L. Lorenzen, S. Miachon, and J.-A. Dalmon, Xylene isomerization in an extractor type Catalytic Membrane Reactor,

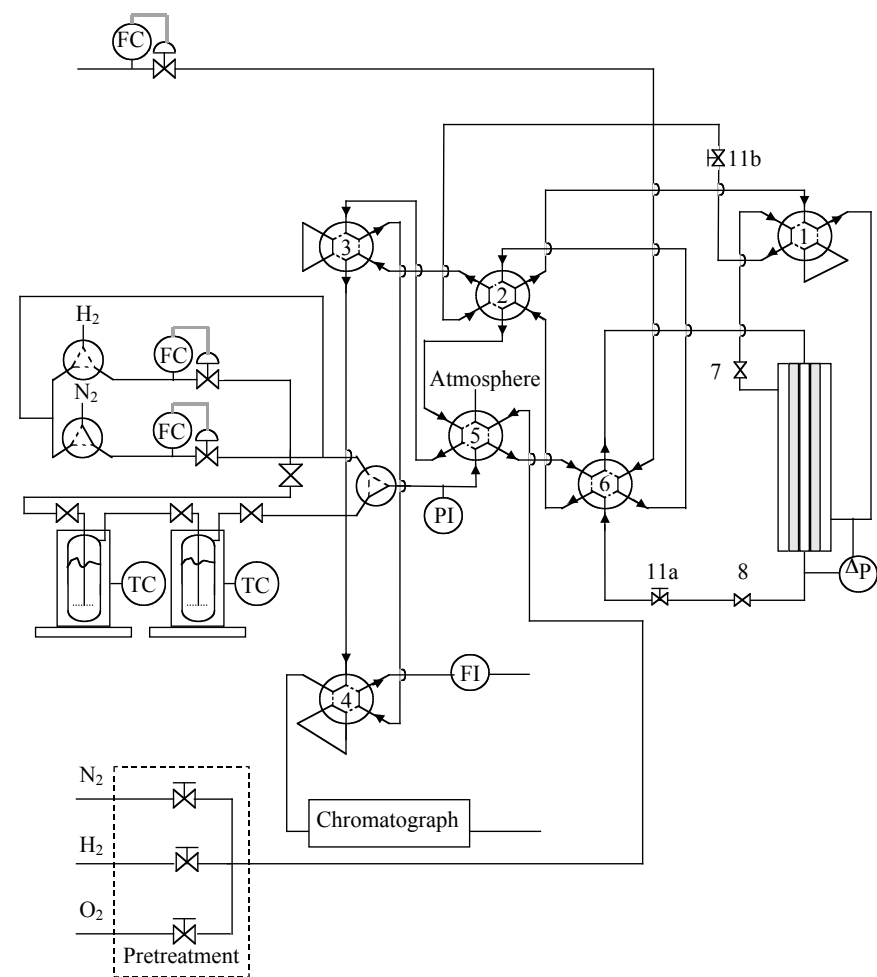

Figure 1. Schematic diagram of the experimental set-up (FC: mass flow controller, $\triangle P$ : transmembrane pressure gauge, FI: flow meter, PI: feed pressure gauge, TC: temperature controllers).

\section{Transport measurements: mixture}

The membrane was sealed with cylindrical graphite seals in a stainless steel module, equipped with temperature control. Before any membrane testing, the MFI membrane was pre-treated at $673 \mathrm{~K}$ under nitrogen flow for 4 hours.

Separation tests were performed on the MFI membrane following a modified Wicke-Kallenbach method with a mixture of xylenes (1.5 kPa p-xylene, $4.5 \mathrm{kPa}$ m-xylene and $1.35 \mathrm{kPa}$ o-xylene) saturated in nitrogen at atmospheric pressure and $336 \mathrm{~K}$. The feeding rate was $60 \mathrm{ml} / \mathrm{min}$ with a counter-current nitrogen sweep of $15 \mathrm{ml} / \mathrm{min}$. The temperature of the membrane system was varied from 673 to $423 \mathrm{~K}$ and again from 423 to $673 \mathrm{~K}$. The feed, retentate and permeate compositions were measured online using the GC.

The separation factor $\left(\mathrm{S}_{\mathrm{f}}\right)$ is defined here as an enrichment factor of one component to another in the permeate, as compared to the feed composition ratio:

$$
S_{f, x / y}=\frac{x_{P} / x_{F}}{y_{P} / y_{F}}
$$

with $x_{F, P}$ and $y_{F, P}$ the molar fractions of components $\mathrm{x}$ and $\mathrm{y}$ in the feed $(\mathrm{F})$ or permeate $(\mathrm{P})$ streams.

\section{CMR operation and set-up}

The fixed bed catalyst was packed in the lumen of the tubular membrane and the m-xylene isomerization reaction was carried out at various temperatures, feed flow rates and sweep flow rates. The differential pressure across the membrane was kept zero by varying the external pressure of the membrane module. Nitrogen was used as a sweep gas in the counter current mode. The feed flow rates were kept high enough to keep the conversion below equilibrium in the catalytic bed, in order to avoid undesired by-product (toluene or ethylbenzene) formation. The permeate and retentate exit streams were analysed separately. Adding up both streams provided the total amount of products obtained in the reactor (combined CMR mode).

We take as our standard conditions: temperature $577 \mathrm{~K}$, $450 \mu \mathrm{l} / \mathrm{min}$ meta-xylene volumetric feed flow rate (diluted in nitrogen up to a total feed flow rate of $7 \mathrm{ml} / \mathrm{min}$ ) and $10 \mathrm{ml} / \mathrm{min}$ sweep flow rate. In both separation and CMR experiments, very little nitrogen back permeation was observed, owing to the limited difference of nitrogen partial pressure between the feed and sweep sides of the membrane.

\section{Conventional fixed-bed Reactor (CR)}

The zeolite-based membrane was replaced with a stainless steel tube of identical dimensions, and the reaction conditions were kept as close as possible to the CMR operation, feeding and analyzing only the retentate side.

\section{Results}

\section{Separation}

Figure 2 shows a diagram of the para-xylene permeance values obtained from the separation testing. Samples were withheld after 90 minute temperature steps starting at $673 \mathrm{~K}$. The temperature was then decreased and samples analysed down to $423 \mathrm{~K}$ and again up to $673 \mathrm{~K}$. Over this temperature range, para-xylene was the only detectable component in the permeate stream. The accuracy/detection limit of the GC corresponded to a permance of about $0.12 \mathrm{nmol} / \mathrm{s} / \mathrm{m}^{2} / \mathrm{Pa}$ for meta-xylene and $0.45 \mathrm{nmol} / \mathrm{s} / \mathrm{m}^{2} / \mathrm{Pa}$ for ortho-xylene, as represented in figure 2 .

Therefore, these results correspond to separation factor values that must be above 73 and 27 for $\mathrm{p}$-/m-xylene as well as above 21 and 7 for p-/o-xylene at 473 and $673 \mathrm{~K}$ respectively. It can be seen in the $673-423 \mathrm{~K}$ range that, in the ternary mixture, para-xylene permeance is a function of temperature with a maximum value of $10.2 \mathrm{nmol} / \mathrm{s} / \mathrm{m}^{2} / \mathrm{Pa}$ at $450 \mathrm{~K}$. The permeance decreases with an increase in temperature, down to a value of about $3.6 \mathrm{nmol} / \mathrm{s} / \mathrm{m}^{2} / \mathrm{Pa}$ at $673 \mathrm{~K}$. The permeance values on the 423 to $673 \mathrm{~K}$ way are similar. 


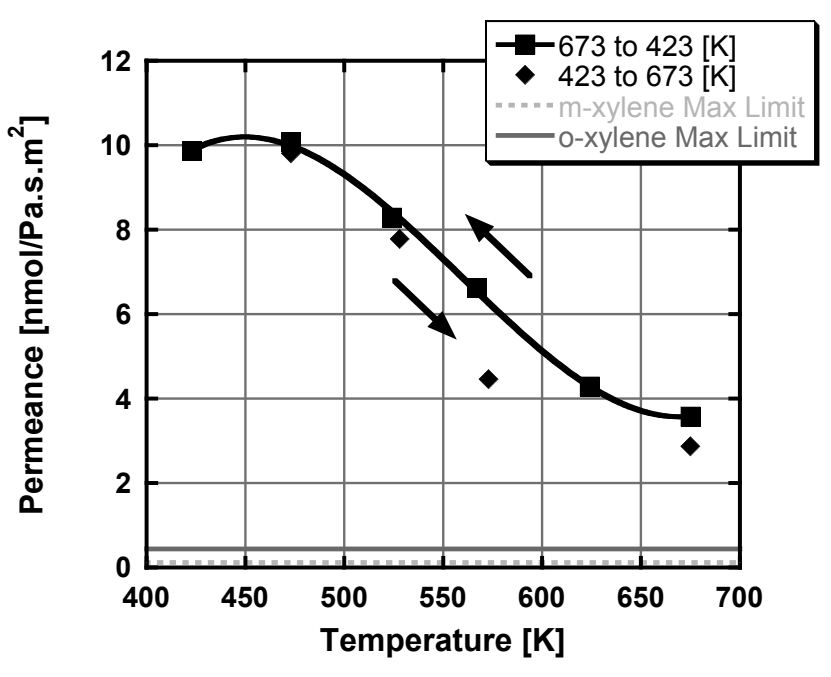

Figure 2. Permeance of para-xylene in a ternary isomer mixture ( \& \& : para-xylene permeance when decreasing and increasing the temperature respectively, dotted gray line: detection limit for meta-xylene, dark gray line, detection limit for ortho-xylene).

\section{Extractor CMR}

Figure 3 is a graphic representation of a typical catalytic membrane reactor result $(577 \mathrm{~K}, 450 \mu 1 / \mathrm{min}$ xylene volumetric feed flow rate, $10 \mathrm{ml} / \mathrm{min}$ counter-current sweep flow rate), showing the feed and exit streams (permeate and retentate) as well as the combination of the two exit streams. The para-xylene yield $(\eta)$ is the amount of formed para-xylene in the stream(s) divided by the total feed. It therefore represents the contribution made by each stream to the total yield in the system. The selectivity (sel) value is the percentage of para-xylene present divided by the amount of reaction products (para + ortho) in each stream.

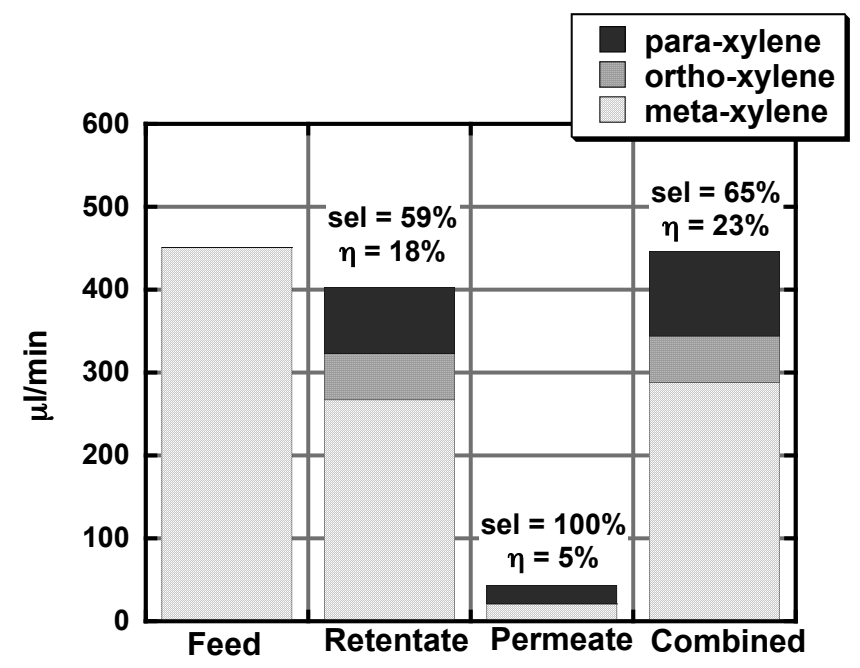

selectivity of para-xylene; $\eta$ : para-xylene yield). The combined result is obtained by mixing of both retentate and permeate streams after the reactor.

The feed to the reactor only includes meta-xylene diluted in nitrogen. Only para-and meta-xylene are detectable in the permeate stream. The para-xylene selectivity in the retentate is $59 \%$, compared to the permeate $100 \%$, meaning all the ortho-xylene formed during the reaction leaves the reaction zone via the retentate stream. The amount of para-xylene in the permeate making up 5\% total para-xylene yield, while the rest leaves the reactor through the retentate. Mixing both streams after the reactor provides the combined CMR mode.

The results obtained for the CMR, operated at the above reaction conditions (referred to as the standard conditions: temperature $577 \mathrm{~K}, 450 \mu \mathrm{l} / \mathrm{min}$ meta-xylene volumetric feed flow rate (diluted in nitrogen) and $10 \mathrm{ml} / \mathrm{min}$ sweep flow rate) are compared with results obtained at a different feed flow rate, temperature and sweep flow rate, and shown in table 1 . The membrane stays para-xylene selective, compared to ortho-xylene at all reaction conditions. If the meta-xylene feed flow rate is increased to $1150 \mathrm{ml} / \mathrm{min}$, the para-xylene yield decrease to $13 \%$ in the retentate and $2 \%$ in the permeate. The selectivity in the permeate remains constant with an increase in feed flow rate, while the selectivity in the retentate increases (up to 66\%) while the yield decreases.

Lowering the sweep flow rate to $7 \mathrm{ml} / \mathrm{min}$ brings about a slight decrease in the para-xylene selectivity of the retentate $(58 \%)$ and permeate yield $(4 \%)$. The paraxylene yield in the retentate stays constant. With an increase in temperature to $633 \mathrm{~K}$, the selectivity in the retentate drops to $55 \%$ indicating a higher ortho-xylene yield for the reaction. The retentate para-xylene yield is $19 \%$, while the permeate para-xylene yield decreases to $4 \%$ rendering an unchanged total para-xylene yield.

Figure 3. CMR operation at $577 \mathrm{~K}, 450 \mu \mathrm{l} / \mathrm{min}$ metaxylene feed, $10 \mathrm{ml} / \mathrm{min}$ sweep flow (sel: 
L. van Dyk, L. Lorenzen, S. Miachon, and J.-A. Dalmon, Xylene isomerization in an extractor type Catalytic Membrane Reactor,

Table 1. Comparison of CMR results at various metaxylene feed flow rates, nitrogen sweep flow rates and temperature, including, as a reference, the standard condition results shown in figure 3 (in italics and between brackets).

\begin{tabular}{|c|c|c|c|c|c|}
\hline \multirow{3}{*}{\multicolumn{2}{|c|}{$\begin{array}{l}\text { (Standard } \\
\text { Conditions) }\end{array}$}} & \multicolumn{2}{|c|}{ Retentate } & \multicolumn{2}{|c|}{ Permeate } \\
\hline & & selectivity & yield & selectivity & yield \\
\hline & & $(59 \%)$ & $(18 \%)$ & \multirow{4}{*}{$100 \%$} & $(5 \%)$ \\
\hline $\begin{array}{c}\text { Feed } \\
{[\mu 1 / \mathrm{min}]}\end{array}$ & $\begin{array}{l}1150 \\
(450)\end{array}$ & $66 \%$ & $13 \%$ & & $2 \%$ \\
\hline $\begin{array}{l}\text { Sweep } \\
{[\mathrm{ml} / \mathrm{min}]}\end{array}$ & $\begin{array}{c}7 \\
(10)\end{array}$ & $58 \%$ & $18 \%$ & & $4 \%$ \\
\hline $\begin{array}{c}\text { Temperature } \\
{[\mathrm{K}]}\end{array}$ & $\begin{array}{l}633 \\
(577)\end{array}$ & $55 \%$ & $19 \%$ & & $4 \%$ \\
\hline
\end{tabular}

In Figure 4, the combined CMR result is compared with the conventional fixed-bed reactor $(\mathrm{CR})$ mode and xylene isomerization equilibrium at $577 \mathrm{~K}$, for the same feed conditions. The CR para-xylene selectivity is $58 \%$ and the para-xylene yield $21 \%$, to be compared to equilibrium values of $46 \%$ and $24.9 \%$, respectively. When the reactor is operated in combined CMR mode, the yield of para-xylene increases slightly (23\%) while para-xylene selectivity $(65 \%)$ increases with $7 \%$ compared to the $\mathrm{CR}$ mode.

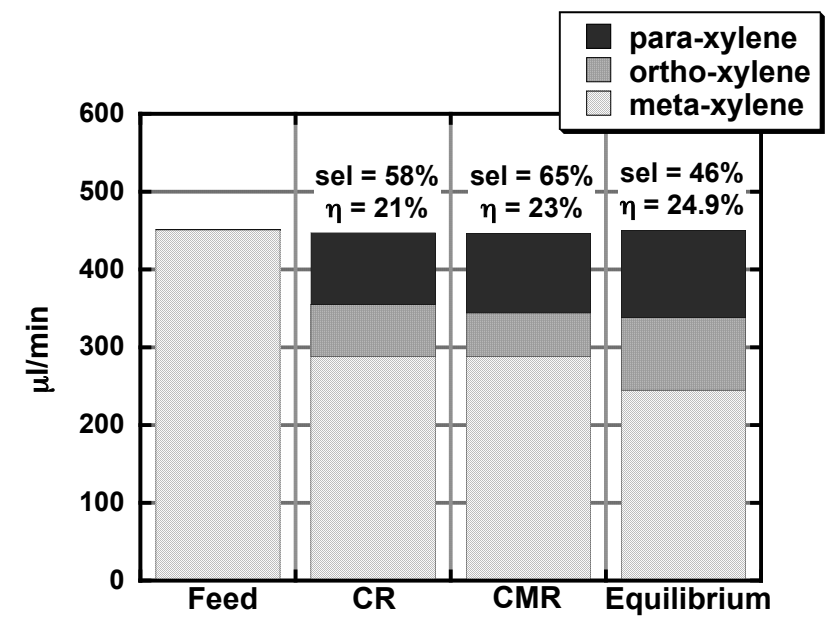

Figure 4. Comparison between conventional fixed-bed reactor (CR), combined mode catalytic membrane reactor (CMR) and xylene isomerization equilibrium [4] at $577 \mathrm{~K}$ (sel: selectivity of para-xylene; $\eta$ : para-xylene yield)

In table 2, the results of the conventional reactor, permeate-only CMR and combined mode CMR are compared in terms of para-xylene selectivity and productivity. The productivity is related to para-xylene per unit bed volume of the reactor.

Table 2. Comparison of Conventional fixed-bed Reactor (CR), Permeate-only (CMR) mode and Combined mode Catalytic Membrane Reactor $(C M R)$

\begin{tabular}{|c|c|c|c|}
\cline { 2 - 4 } \multicolumn{1}{c|}{} & $\begin{array}{c}\text { Conventional } \\
\text { Reactor (CR) }\end{array}$ & $\begin{array}{c}\text { Permeate- } \\
\text { only } \\
\text { (CMR) }\end{array}$ & $\begin{array}{c}\text { Combined } \\
\text { mode } \\
\text { CMR }\end{array}$ \\
\hline $\begin{array}{c}\text { Para-xylene } \\
\text { selectivity }\end{array}$ & $58 \%$ & $100 \%$ & $65 \%$ \\
\hline $\begin{array}{c}\text { Productivity } \\
\left(\mathrm{mmol} / \mathrm{s} / \mathrm{m}^{3}\right)\end{array}$ & 10.2 & 2.4 & 11.2 \\
\hline
\end{tabular}

\section{Discussion}

From the separation experiment results it can be concluded that para-xylene can be selectively separated from a ternary mixture of xylene isomers with the MFI zeolite membranes prepared in this study. A maximum value in the permeance of para-xylene can be seen close to $450 \mathrm{~K}$. It can be explained as follows: as we consider the transport to be controlled by the zeolite pores, it is driven by a competition between adsorption and diffusivity temperature dependence. At low temperatures the coverage of para-xylene on the pore surface is higher. With an increase in temperature the coverage decreases, and is counterbalanced by the increase of the diffusion coefficient up to a certain point, leading to a further global decrease in permeance, as observed for all gases previously studied on this type of membrane [18-22].

It is interesting to note this study did not provide any hint of further permeance increase at higher temperatures, as commonly quoted (gas activated transport) on different gases $[8,9,23-25]$ and also on xylenes $[6,7,9,10]$. This may be related to the support pore-plugging structure of the membrane, and will be detailed in another paper [26].

Meta-xylene isomerization in an extractor catalytic membrane reactor leads to an increase in the para-xylene selectivity of the reaction. This is due to the selective extraction of para-xylene compared to ortho-xylene. Throughout the runs no ortho-xylene was detected in the permeate stream. The meta-xylene present in the permeate stream may be due to permeation of metaxylene in the first part of the reactor, when the paraxylene concentration is still too low to block the zeolite pores by adsorption [27]. As a matter of fact, calculations based on a para/meta-xylene separation factor above 53 at the reaction temperature, assuming an averaged lumen gas composition after reaction close to that used in the 
separation experiments, were carried out. They suggest that the observed meta-xylene trans-membrane flow is far too high when compared to separation conditions.

An increase in meta-xylene feed flow rate decreases the overall conversion of meta-xylene. The fact that the paraxylene selectivity improves in the retentate stream indicates that the reaction becomes more para-xylene selective at higher feed rates, as could be expected. The amount of para-xylene that diffuses also decreases, due to the concentration decrease of para-xylene in the membrane reaction zone.

It is expected that with a decrease in sweep flow rate the para-xylene permeance would also decrease. This has been seen for hydrogen extraction in CMR experiments with similar membranes as used in this study [28]. With a decrease in sweep flow rate from 10 to $7 \mathrm{ml} / \mathrm{min}$ a small decrease in para-xylene permeance is observed. This, together with the fact that the yield of para-xylene in the retentate stays constant while the para-xylene selectivity in the retentate also decreases slightly, indicates that when less para-xylene is extracted, more ortho-xylene is formed in the reaction.

When the temperature is changed from 577 to $633 \mathrm{~K}$, the selectivity in the retentate decreases indicating more ortho-xylene production at this temperature. The yield in the retentate is only slightly higher, but the yield in the permeate is lower indicating the effect of temperature on the para-xylene permeance from the mixture, as seen during the separation testing.

When the yield and para-xylene selectivity values (fig. 4) of the conventional fixed-bed reactor and those calculated using thermodynamic equilibrium are compared, it is clear that the reactor is not operated at equilibrium. A WHSV of $\$ 151 \mathrm{hr}^{-1}$ was used in these conditions. CMR operation increases the reaction selectivity when compared to conventional conditions, due to the fact that no ortho-xylene is present in the permeate stream. The results obtained for the conventional fixed-bed reactor is similar to that of the retentate (sel $=59 \%$ and $\eta=20 \%)$. A relative improvement in para-xylene yield of about one tenth (23\% compared to $21 \%$ ) is achieved. It is expected that this improvement can be enhanced upon if no metaxylene was present in the permeate stream.

If one considers the CMR in the permeate-only mode, when compared to $\mathrm{CR}$, the para-xylene selectivity is improved up to $100 \%$ - almost double. This would however lead to a significant reduction in the para-xylene production throughput (2.4 compared to $10.2 \mathrm{mmol} / \mathrm{m}^{3} / \mathrm{s}$ ). However, when the catalytic membrane reactor is used in combined mode (mixing both the retentate and permeate feed after the reactor), the paraxylene productivity is noticeably increased over the conventional fixed-bed reactor (11.2 compared to 10.2 $\mathrm{mmol} / \mathrm{m}^{3} / \mathrm{s}$ ) with a lower amount of ortho-xylene in the product. This demonstrates that including both the separative membrane, and the catalytic bed in the same device (as per definition of a CMR) leads to an improvement when compared to separated catalytic and membrane separation units.

\section{Conclusions}

Using an extractor type catalytic membrane reactor instead of a conventional fixed-bed reactor for metaxylene isomerization, can lead to higher para-xylene selectivities. The para-xylene selectivity can even be improved to $100 \%$ if the CMR is operated in the permeate-only mode, but this comes at a price of lower para-xylene yields. When operated in combined mode (i.e. mixing both permeate and retentate streams after the reactor), the CMR shows an improvement on both paraxylene productivity and selectivity when compared to the conventional fixed-bed reactor.

To the best of our knowledge there are no comparable results in literature. Research on xylene isomerization in a MFI membrane reactor was conducted by Mabanda et al.[29], but their results indicated that the separation of xylenes through the membrane was not sufficient enough to improve on the performance of the conventional fixedbed reactor.

\section{Prospects}

Further improvements on the system are necessary, with higher cross-membrane para-xylene fluxes being the most important. Optimizing the zeolite membrane (in performance and/or geometry), the catalyst location along the membrane and/or working under higher feed xylene partial pressures may achieve this. In particular, the observed permeation of meta-xylene through the membrane during CMR operation could benefit from pre-conversion of meta-xylene or recycling of the permeate.

The catalyst needs to be optimised in order to ensure no undesirable by-products at equilibrium, for example ethylbenzene, would compete with para-xylene to diffuse through the membrane. Operation of the CMR at lower temperatures is necessary to investigate the advantages of the higher para-xylene permeance at lower temperatures. These two arguments show once again, that catalysts for CMRs need specific designs [28,30].

Modeling and scale-up studies are also needed to investigate the practical and economical feasibility of this process.

\section{Acknowledgements}

The authors would like to thank Süd-Chemie for kindly providing the catalyst and the Centre National de la Recherche Scientifique (Direction des Relations 
L. van Dyk, L. Lorenzen, S. Miachon, and J.-A. Dalmon, Xylene isomerization in an extractor type Catalytic Membrane Reactor,

Internationales) and National Research Foundation (South Africa) for financial assistance.

Special thanks to Emmanuel Landrivon for technical help.

\section{References}

[1] G. Graph, Purchasing Magazine (2003) [http://www.manufacturing.net/pur/].

[2] J.J. McKetta, Encyclopedia of Chemical Processing and design, Marcel Dekker Inc., New York, 1999.

[3] M. Guisnet, N.S. Gnep, S. Morin, Microporous and Mesoporous Materials, 35-36 (2000) 47.

[4] R.D. Chirico, V. Steele, Journal of Chemical Engineering Data, 42 (1997) 784.

[5] C.D. Baertsch, H.H. Funke, J.L. Falconer, R.D. Noble, Journal of Physical Chemistry, 100 (1996) 7676.

[6] G. Xomeritakis, L. Zhiping, M. Tsapatsis, Industrial \& Engineering Chemistry Research, 40 (2001) 544.

[7] H. Sakai, T. Tomita, T. Takahashi, Separation and Purification Technology, 25 (2001) 297.

[8] C.L. Flanders, V.A. Tuan, R.D. Noble, J.L. Falconer, Journal of Membrane Science, 176 (2000) 43.

[9] C.J. Gump, V.A. Tuan, R.D. Noble, J.L. Falconer, Industrial Engineering and Chemistry Research, 40 (2000) 565.

[10] K. Keizer, A.J. Burggaaf, Z.A.E.P. Vroon, H. Verweij, Journal of Membrane Science, 147 (1998) 159.

[11] G. Xomeritakis, S. Nair, M. Tsapatsis, Microporous Mesoporous Materials, 38 (2000) 61.

[12] G. Xomeritakis, S. Nair, M. Tsapatsis, Chemical Materials, 11 (1999) 875.

[13] J. Hedlund, J. Sterte, M. Anthonis, A.-J. Bons, B. Cartensen, N. Corcoran, D. Cox, H. Deckman, W. De Gijnst, P.-P. de Moor, F. Lai, J. McHenry, W. Mortier, J. Reinoso, J. Peters, Microporous and Mesoporous Materials, 52 (2002) 179.

[14] J. Hedlund, F. Jareman, A.-J. Bons, M. Anthonis, Journal of Membrane Science, 222 (2003) 163.

[15] Z. Lai, G. Bonilla, I. Diaz, J.G. Nery, K. Sujaoti, M.A. Amat, E. Kokkoli, O. Terasak, R.W. Thompson, M. Tsapatsis, D.G. Vlachos, Science, 300 (2003) 456.

[16] Z. Lai, M. Tsapatsis, Industrial \& Engineering Chemistry Research, 43 (2004).

[17] J.-A. Dalmon, in G. Ertl, H. Knözinger, J. Weitkamp (Editors), in Handbook of
Heterogeneous Catalysis, VCM Publishers, Weinheim, 1997, p. 2541.

[18] C. Chau, I. Prévost, S. Miachon, J.-A. Dalmon, Patent 02290252.2-2113 (US6.582.495) (Europe), 4.02.2001 (ext. to US 24.06.2003).

[19] A. Giroir-Fendler, J. Peureux, H. Mozzanega, J.A. Dalmon, Studies in Surface Sciences and Catalysis, 101A (1996) 127.

[20] P. Ciavarella, D. Casanave, H. Moueddeb, S. Miachon, K. Fiaty, J.-A. Dalmon, Catalysis Today, 67 (2001) 177.

[21] P. Ciavarella, H. Moueddeb, S. Miachon, K. Fiatty, J.-A. Dalmon, Catalysis Today, 56 (2000) 253.

[22] D. Casanave, A. Giroir-Fendler, J. Sanchez, R. Loutaty, J.-A. Dalmon, Catalysis Today, 25 (1995) 309.

[23] S. Sommer, T. Melin, J.L. Falconer, R.D. Noble, Journal of Membrane Science, 224 (2003) 51.

[24] R.D. Noble, J.L. Falconer, Catalysis Today, 25 (1995) 209.

[25] C. Bai, M.-D. Jia, J.L. Falconer, R.D. Noble, Journal of Membrane Science, 105 (1995) 79.

[26] I. Kumakiri, O. Pachtova, S. Miachon, H. Mozzanega, E. Landrivon, Y. Sun, N.

Guilhaume, J.-A. Dalmon, Journal of Membrane Science (to be submitted).

[27] T. Masuda, T. Asanuma, M. Shouji, S.R. Mukai, M. Kawase, K. Hashimoto, Chemical Engineering Science, 58 (2003) 649.

[28] L. van Dyk, S. Miachon, L. Lorenzen, M. Torres, K. Fiaty, J.-A. Dalmon, Catalysis Today, $82(2003) 167$.

[29] G.T.P. Mabande, A. Avhale, W. Schwieger, M. Hanebuth, R. Dittmeyer, (Proc. of 6th International Conference on Catalysis in Membrane Reactors (ICCMR-6)) (2004).

[30] S. Miachon, J.-A. Dalmon, Topics in Catalysis, 29 (2004) 59. 